\title{
A educação de professores de línguas em CALL: histórico e perspectivas
}

\author{
Ana Cristina Biondo Salomão \\ PPGEL-UNESP - São José do Rio Preto \\ anacbsalomao@yahoo.com.br
}

\section{Resumo}

Nos últimos anos, as novas tecnologias têm mudado o modo como nos relacionamos com a informação e nos comunicamos com as pessoas, o que trouxe impactos para o ensino e aprendizagem de línguas estrangeiras e, consequentemente, para a área de formação de professores de línguas. A sigla CALL (Computer Assisted Language Learning) tem sido usada para designar os processos de ensino e aprendizagem de línguas com a utilização de computadores, e o termo educação de professores em CALL para nomear a formação de professores para e com o uso das novas tecnologias, uma vez que vários autores indicam a interdependência entre ambos os processos. Pretendemos, neste artigo, apresentar um panorama da literatura da área da educação de professores de línguas em CALL na atualidade e discutir questões relacionadas ao uso de novas tecnologias no que tange à integração, à formação e aos novos papéis funcionais e institucionais dela advindos. Apresentaremos, ainda, duas propostas de formação de professores com o uso de tecnologias em fase de implementação e pesquisa no Brasil. Acreditamos que elas contam com elementos essenciais para o desenvolvimento de professores para e com o uso das novas tecnologias nos dias atuais.

Palavras-chave: formação de professores de línguas, tecnologias da informação e comunicação, aprendizagem de línguas mediada por computador.

\footnotetext{
Abstract

Over the last years, the new technologies have changed the way we relate to information and communicate with other people, which has brought on impact
} 
to foreign language teaching and learning, and, consequently, to the area of foreign language teacher education. The abbreviation CALL (Computer Assisted Language Learning) has been used to designate the processes of language teaching and learning with the use of computers, and language teacher education in CALL to name teacher education for and with the use of new technologies, since a number of authors point to the interdependence of both processes. We intend in this article to present an overview of the literature of the area of language teacher education in CALL nowadays and discuss issues related to the use of new technologies concerning its integration to teacher education and the functional and institutional roles to be taken. We also present two proposals of teacher education with the use of new technologies which are being implemented and at the same time studied in Brazil, which we believe have essential elements for the development of language teachers for and with the use of new technologies currently.

Keywords: language teacher education, information and communication technologies, CALL.

\section{Introdução}

O ensino e aprendizagem de línguas nos últimos anos tem incorporado o uso das Novas Tecnologias da Informação e Comunicação (NTIC), competindo por um espaço no currículo da educação linguística e se tornando foco de pesquisas, o que se convencionou chamar de computer-assisted language learning (CALL) - aprendizagem de línguas assistida pelo computador. Vários autores, dentre eles Richards (2002), evidenciam o aumento do uso de recursos tecnológicos, principalmente os relacionados com computadores, como uma característica comum em salas de aula de língua estrangeira. Richards (op. cit.) afirma que não há dúvida de que eles ocuparão cada vez mais um papel central nesses contextos no futuro, mas reafirma a importância do professor como determinante da qualidade do aprendizado em meio ao uso dos recursos que as novas tecnologias disponibilizam. $\mathrm{O}$ autor, inspirando-se nas discussões de Jones \& Sato (1998), questiona também o fato de os professores estarem ou não preparados para trabalhar com elas:

As novas tecnologias facilitam o alcance dos objetivos do curso? (...) Os professores estão preparados para trabalhar com a nova tecnologia? É necessário algum treinamento 
(formação)? Ela atende às necessidades de ambos os professores e os alunos? Ela ajuda os professores a fazer uso mais eficiente do período de aula? (RICHARDS, 2002, p.361).

Tais questionamentos demonstram o impacto que o uso das NTIC trouxe também para a área de formação de professores, que busca agora incorporar reflexões sobre seu uso eficaz no processo de ensino e aprendizagem juntamente com o papel do professor e sua formação. Hubbard (2008) afirma que o futuro de CALL está intimamente relacionado ao futuro da educação de professores de línguas porque os professores têm um papel crucial, uma vez que selecionam as ferramentas que darão suporte ao ensino e determinam os aplicativos e a maneira de usá-los, mas ainda não podem contar com boas propostas relacionadas ao uso de CALL nos livros didáticos de língua estrangeira, especialmente os dirigidos à educação básica.

Para Chapelle (2006), existe uma ansiedade e incerteza sobre o quê e como ensinar atuais e futuros professores de línguas sobre tecnologia, de modo a prepará-los para o enfrentamento das novas demandas sociais da era do ciberespaço. Segundo a autora, os próprios educadores de professores têm um conhecimento parcial e frágil da área de CALL, o que é agravado pela complexidade da pesquisa e da prática nesta área, e também pela rapidez com que as mudanças geralmente ocorrem nela. Chapelle (op.cit.) afirma que os questionamentos sobre a educação de professores em CALL são basicamente os mesmos sobre a educação de professores de maneira geral:

Como balancear a teoria e a prática em CALL? Além disso, em que consistem teoria e prática em CALL? Qual é a base de conhecimentos sobre CALL que deveria ser transmitida ou descoberta pelos alunos-professores em formação? Que conhecimento técnico o professor de línguas deve ter para poder se engajar em um trabalho de descoberta em CALL?

\footnotetext{
${ }^{1}$ No original: "Does the technology facilitate the attainment of course goals? (...) Are the teachers ready to work with the new technology? Is any training required? Does it serve the needs of the teachers and students? Does it help teachers make more efficient use of class time?"
} 
Quais áreas de CALL e quais abordagens de CALL deveriam ser incluídas? (CHAPELLE, 2006, p. VIII) ${ }^{2}$

Desse modo, as preocupações na educação de professores mediadas pelas tecnologias e direcionadas ao uso delas para o ensino e aprendizagem de línguas incorporam os antigos questionamentos sobre o entrecruzamento de teoria e prática. Acrescenta-se à discussão do domínio linguístico e pedagógico aspectos de instrumentalização do professor para usar a ferramenta, conhecer seus recursos e aplicativos, além de atingir um nível reflexivo e crítico sobre ela.

Pretendemos, neste artigo, apresentar um panorama da literatura da área da educação de professores em CALL na atualidade, e discutir questões relacionadas ao uso de novas tecnologias no que tange à formação, aos papéis funcionais e institucionais requeridos dos profissionais que nela atuam (ou atuarão) e à integração das novas tecnologias à formação por meio de cursos a distância ou cursos híbridos. Apresentaremos, ainda, duas propostas de formação de professores com o uso de tecnologias em fase de implementação e pesquisa no Brasil.

\section{Educação de professores em CALL}

Segundo Hall e Knox (2009), a literatura sobre educação de professores com o uso de tecnologias é bastante recente, datando de meados da década de 1990. Os autores afirmam que diferentemente da literatura sobre educação de línguas a distância e em ambientes de ensino e aprendizagem de línguas on-line, cuja produção tem crescido amplamente (citam KERN, 2006; KERN et al., 2004; WHITE, 2003, 2006), não há, até agora, uma ampla revisão de pesquisas conduzidas a respeito do uso da tecnologia para a formação de professores de línguas. Portanto, não há um claro panorama sobre o que é conhecido,

\footnotetext{
2 No original: "How does one strike an appropriate balance between theory and practice in CALL? Moreover, what do theory and practice consist of in CALL? What is the professional knowledge base about CALL that should be transmitted to or discovered by students studying CALL in graduate programs? What technical knowledge does a language teacher need to encourage in discovery work in CALL? What areas of CALL and approaches to CALL should be included?"
} 
onde estamos ou se há uma agenda de trabalhos futuros. Os autores afirmam ainda que há relativamente poucos estudos publicados que examinam diretamente a educação de professores a distância, e que em geral eles são predominantemente estudos de caso sob a perspectiva do instrutor, compreendendo a descrição de um programa ou o processo de desenvolvimento de um curso a distância. Para eles, faltam mais estudos que empreguem triangulação de dados na análise e reflitam sobre a natureza dos materiais da pedagogia, da aprendizagem ou do currículo em tais contextos.

Hubbard e Levy (2006) indicam a escassez de publicações sobre o uso de tecnologias na educação de professores de línguas. Segundo esses autores, algumas diretrizes sobre competência tecnológica para professores e para alunos foram publicadas entre o final de 1990 e início de 2000, entretanto elas destinavam-se a informar a educação em geral, e um campo tão específico como a formação de professores de línguas deveria ter cautela ao fazer uso de critérios educacionais genéricos.

Alguns desenvolvimentos na área foram feitos pelo American Council of Teaching of Foreign Languages (ACTFL) e pelo Conselho Europeu, com a publicação de diretrizes voltadas ao ensino de línguas e as competências tecnológicas. No entanto, para Hubbard e Levy (p.cit.), corre-se o risco de assumir uma abordagem de "boas práticas", a qual marginaliza conceitualizações alternativas ao institucionalizar visões predominantes ou "eficazes". Os autores afirmam que outras tendências têm se desenvolvido no estudo da formação de professores em CALL:

(...) nós reconhecemos quatro fortes tendências na educação de professores: 1) a produção de materiais de treinamento (formação) e suporte orientados diretamente aos professores de salas de aula; 2) uma pequena, porém crescente, produção de literatura da área da educação de professores em CALL voltada para a prática e para a pesquisa; 3) a elaboração de estruturas que definem a prática da CALL baseadas em princípios derivados de abordagens de aprendizagem de línguas específicas, especialmente da pesquisa em aquisição de segunda língua; 4) o uso de técnicas colaborativas de aprendizagem on-line na educação de professores de línguas em CALL com um crescente 
interesse na qualidade da transferência das habilidades e conhecimentos dos cursos formais para a sala de aula. (HUBBARD; LEVY, 2006, p. 5)

Segundo os autores, há necessidade, atualmente, de se contemplar as seguintes questões no que tange à educação de professores e ao uso de novas tecnologias:

1) a necessidade de treinamento técnico e pedagógico em CALL, idealmente integrados um ao outro;

2) o reconhecimento dos limites do ensino formal porque as tecnologias mudam rapidamente;

3) a necessidade de associar a educação em CALL a contextos de ensino autênticos, especialmente aquele nos quais os equipamentos, softwares e suporte tecnológico se diferenciam do ideal;

4) a ideia de usar CALL para aprender sobre CALL - experimentar as aplicações tecnológicas na educação primeiramente como aluno para aprender a usar a tecnologia como professor;

5) o valor de CALL permear o currículo da educação do professor de línguas em vez de aparecer somente como um curso isolado.

Hubbard e Levy (2006) evidenciam que os contextos, nos quais os profissionais possuem papéis funcionais e institucionais, determinam o nível de conhecimento tecnológico que o professor deve apresentar. Os papéis funcionais dizem respeito ao que o indivíduo faz em relação ao CALL: prático, desenvolvedor, pesquisador e treinador (practitioner, developer, researcher, trainer). Os papéis institucionais

\footnotetext{
${ }^{3}$ No original: "we can recognize four general trends in CALL education: 1) the production of training and support materials directly oriented toward classroom teachers; 2) a small but growing literature in CALL teacher education itself at the levels of both research and practice; 3) frameworks that attempt to define CALL practice on the basis of principles derived from particular language teaching approaches, especially those supported by SLA (second language acquisition) research; 4) the use of online collaborative learning techniques in CALL teacher education with a growing interest in the quality of skills and expertise from formal courses to the language classroom."
} 
relacionam-se às responsabilidades e aos níveis de conhecimento dele esperados dentro de uma organização: o professor da sala de aula, o especialista em CALL e o profissional de CALL (classroom teacher, CALL specialist, CALL professional).

Segundo os autores, como os papéis funcionais estão relacionados a ações, eles são mais dinâmicos do que os papéis institucionais, ou seja, é comum para uma pessoa alternar papéis funcionais rapidamente, geralmente de modo integrado a uma atividade ou tarefa específica. Por exemplo, como desenvolvedor, na sala de aula, o professor pode criar uma nova tarefa em CALL na qual os alunos tenham que empregar informação da Internet e discuti-la online para um projeto prático em grupo. $\mathrm{Na}$ qualidade de práticoele determinaria as maneiras de: integrar essa tarefa ao curso, apresentá-la para os alunos, organizar os grupos, estabelecer objetivos, gerenciar o progresso e prover feedback ao final. Com a função de treinador, ele proveria instruções para a operação técnica dos aplicativos no computador além de estabelecer estratégias para relacionar suas ações aos objetivos de aprendizagem. Como pesquisador, ele poderia revisar os itens postados pelos alunos para identificar estruturas, léxico ou padrões de interação que possam informar atividades posteriores em sala ou versões futuras da mesma tarefa. Os papéis institucionais são geralmente mais estáveis e envolvem rótulos institucionais; ou seja, com o mesmo papel institucional, o profissional poderá ter papéis funcionais distintos em momentos diferentes, de acordo com a atividade desempenhada e com a necessidade por ela gerada.

Os pares de papéis funcionais-institucionais são caracterizados em dois domínios: técnico e pedagógico. Ambos apresentam os componentes conhecimento e habilidade, conforme sintetizado no Quadro 1, retirado e traduzido de Hubbard e Levy (2006):

\begin{tabular}{|c|c|c|}
\hline & Técnico & Pedagógico \\
\hline $\begin{array}{l}\text { Conhecimento } \\
\text { em CALL }\end{array}$ & $\begin{array}{l}\text { Compreensão sistemática e } \\
\text { incidental do sistema } \\
\text { computacional, incluindo } \\
\text { aparelhos periféricos, em } \\
\text { termos de hardware, } \\
\text { software e rede. }\end{array}$ & $\begin{array}{l}\text { Compreensão sistemática e } \\
\text { incidental das maneiras de } \\
\text { usar o computador } \\
\text { eficazmente no ensino de } \\
\text { línguas. }\end{array}$ \\
\hline
\end{tabular}




\begin{tabular}{|llllr|}
\hline Habilidade em & Habilidade para usar & Habilidade de & usar \\
CALL & conhecimento e experiência & conhecimento & e \\
& técnicos para a operação do & experiência & para \\
& sistema computacional e & determinar & matérias, \\
& aplicações relevantes e em & conteúdo e tarefas eficazes \\
& lidar com vários tipos de & e monitorar e avaliar os \\
& problemas. & & resultados adequadamente. \\
\hline
\end{tabular}

Quadro 1: Domínios e componentes da educação em CALL

À primeira vista, a separação entre conhecimento e habilidade feita pelos autores parece se assemelhar à distinção entre teoria e prática, ou ao conhecimento declarativo e ao procedimental, o que poderia gerar possíveis críticas. Os autores explicam as razões para tal distinção alegando que ela traz vantagens, como, por exemplo, o fato de que, no nível técnico, é comum aprender uma sequência fixa de ações as quais produzem um resultado desejado: salvar um arquivo, por exemplo. No entanto, muitas vezes o indivíduo não sabe como agir se algo der errado, caso não possua um conhecimento de base sobre o que tal sequência representa em termos de interação com software e hardware.

Essa tentativa de escrutinizar os aspectos envolvidos nas dimensões técnica e pedagógica da atuação do profissional da educação de línguas em CALL em questão teve a finalidade de tentar estabelecer necessidades específicas de treinamento e formação para cada papel funcional ou institucional desempenhado pelo profissional da educação de línguas ao utilizar-se de ferramentas e recursos tecnológicos. Entretanto, se por um lado ela ajuda a esclarecer alguns aspectos necessários para a interação do professor com as ferramentas e seu uso didático, por outro, não oferece caminhos alternativos para a formação de professores na medida em que compartimentaliza os conhecimentos e as habilidades. Também não explica como os recursos devem ser incorporados ao currículo da formação, o que gera mais questionamentos, dentre os quais: Como é adquirido o conhecimento sobre o sistema computacional? Seriam necessárias noções sobre programação de computadores para isso? Como os formadores lidariam com isso? Precisaríamos incorporar profissionais de outras áreas, como da ciência da computação? 
Hubbard e Levy (2006), ao preverem críticas e questionamentos a respeito do quadro por eles elaborado, reconhecem suas limitações e ressaltam que têm o objetivo de apresentar uma abordagem descritiva e não prescritiva.. Segundo os autores, a intenção é auxiliar este estágio inicial de fazer com que elementos que compõem a educação de professores em CALL sejam tratáveis ("tractable"), demonstrando uma aparente necessidade de desmembrar o todo em partes para que ele possa ser (re)conhecido - o que nos leva a alinhá-la com uma interpretação atomista da realidade. Apesar de atraente, perguntamo-nos se esta ideia não seria uma volta à antiga posição dicotômica entre teoria e prática, ou à relação de contraste entre dois tipos de conhecimento necessários - o conhecimento sobre (knowledge about), ou seja, o conhecimento do conteúdo e o conhecimento prático (knowledge how).

Do mesmo modo, a afirmação de Reinders (2009) de que os professores precisam dominar as habilidades técnicas para usar as tecnologias antes de descobrirem como implementá-las também se assemelha à distinção entre treinamento e desenvolvimento. É interessante notar que ao mesmo tempo em que faz essa distinção, o autor afirma que não defende a separação de cursos de tecnologia e ensino, alegando que seria questionável afirmar que o conhecimento adquirido no primeiro se traduziria em prática na sala de aula, mas propõe que uma visão integrada, na qual a tecnologia permeia os cursos de formação. A nosso ver, também, o treinamento e o conhecimento devem ocorrer juntos uma vez que os usos técnicos e didáticos da ferramenta se complementam e, possivelmente, medeiam a aprendizagem um ao outro, se relacionados às atividades concretas vivenciadas em contextos sociais, como parte integrante do currículo de um curso de formação com objetivos mais amplos. Diferentemente do que ocorreria em um curso isolado para ensinar a usar a ferramenta, já que os conhecimentos e as habilidades aprendidos podem ser descontextualizados e facilmente esquecidos.

Reinders (2009) também discute diferentes modos de abordar a tecnologia na educação de professores, refletindo sobre outras duas dicotomias a serem levadas em consideração ao se pensar sobre a abordagem escolhida: a tecnologia deve ser integrada de modo formal ou informal? Genérico ou específico? 
Em relação à abordagem formal ou informal, o autor afirma que muitos professores aprendem a usar tecnologias informalmente, por curiosidade e com a ajuda de colegas. Para ele, as abordagens formais poderiam trazer resultados mais consistentes em nível institucional, não se devendo descartar as contribuições de cada uma . Quanto à educação tecnológica genérica ou específica, Reinders (2009) afirma que apesar do potencial benefício de uma abordagem genérica que possa prover habilidades independentes de uma ferramenta ou de uma tecnologia específica, corre-se o risco de fazer com que tal curso seja muito abstrato e não imediatamente relacionado às demandas enfrentadas pelos professores. Por outro lado, ensinar a usar um número de programas específicos é geralmente mais rápido, mas tem as desvantagens da necessidade de atualização cada vez que o programa ganha uma nova versão.

Conforme constatamos, a discussão por meio de dicotomias somente leva à percepção de vantagens e desvantagens de cada abordagem, o que nos leva pensar que discussões mais profícuas na contemporaneidade sejam aquelas que tentam cingir dualidades dicotômicas, a fim de buscar um entremeio que ofereça caminhos tangíveis e eficazes. Para tornar mais claro nosso argumento aqui explicitado, citamos outra afirmação de Reinders (2009): a de que no futuro, um dos desafios para os professores deverá ser o de desenvolver as habilidades para lidar, com sucesso com o crescente controle e independência que a tecnologia exige. Tal afirmação surpreende por apresentar um paradoxo: como algo pode representar controle e independência ao mesmo tempo? A chave parece estar na eliminação das dicotomias, o que, no exemplo citado, pode ser resolvido pela busca por uma interdependência entre os sujeitos e as ferramentas, envolvendo controle e independência de modo interligado, com base em uma perspectiva sociocultural que reconheça as relações sociais e o contexto na interpretação da realidade.

Os princípios epistemológicos da perspectiva sociocultural derivam dos trabalhos do educador e psicólogo russo Lev Vygotsky e seus seguidores Leont'ev e Luria, citados por Johnson (2009). A autora afirma que mais recentemente essa perspectiva tem sido estendida por estudiosos como Cole (1996), Lantolf (2000, 2006), Wertsch (1991), entre outros. De acordo a perspectiva sociocultural, a cognição humana é formada por meio do engajamento em atividades sociais, e são as 
relações sociais e os materiais, signos e símbolos culturalmente construídos, denominados artefatos semióticos, que medeiam as relações que criam formas de pensamento humano superiores. Consequentemente, desenvolvimento cognitivo é um processo interativo, mediado por: cultura, contexto, linguagem e interação social (JOHNSON, 2009). O significado não reside na linguagem em si, mas no uso social dela e, portanto, o desenvolvimento cognitivo é caracterizado como a aquisição e a manipulação de ferramentas culturais e de conhecimento.

Acreditamos que a abordagem sociocultural possa trazer os entremeios que há que se buscar para uma formação de professores em CALL na atualidade, uma vez que tal perspectiva enfatiza o papel do agenciamento humano no processo de desenvolvimento. Também reconhecemos que a aprendizagem não é a apropriação direta de habilidades e conhecimento de fora para dentro, mas o movimento contínuo de atividades externas, socialmente mediadas para o controle mediacional interno dos aprendizes individualmente, que resulta na transformação tanto da pessoa quanto da atividade. Como e o quê o indivíduo aprende e como isso é usado dependerá de suas experiências prévias, dos contextos socioculturais nos quais a aprendizagem ocorre e do que o indivíduo quer, necessita e/ou deve fazer com aquele conhecimento.

\section{Modalidades de educação de professores com uso de tecnologia}

A integração das novas tecnologias à formação de professores de línguas tem ocorrido de diferentes formas, por meio de cursos a distância ou cursos híbridos, ou seja, aqueles que mesclam atividades a distância com outras feitas presencialmente.

Hall e Knox (2009) consideram que aprendizagem a distância não é algo novo, ela pode ser encontrada nas antigas tradições gregas e judaicas. Eles acrescentam que cursos por correspondência eram oferecidos no século XVIII nos EUA e no início do século XIX no Reino Unido. Segundo os autores, recentemente, tem-se desenvolvido uma forte relação entre educação a distância e formação do professor, e 
pesquisas mostram que há programas de formação de professores a distância em quase todos os lugares do mundo, mas que as opções são ainda limitadas. Além disso, muitas das instituições que fornecem cursos a distância são instituições particulares que oferecem certificados em vez de títulos acadêmicos.

Com base em Mood (1995), os autores descrevem quatro características básicas da educação a distância: a separação física entre professor e aluno; a influência ou controle de uma instituição educacional organizada; o envolvimento de mídia; e comunicação de mão dupla. Os autores adicionam uma quinta qualidade da educação a distância: há pouca ou nenhuma exigência para os alunos comparecerem fisicamente à instituição em que estudam, mas alertam que cada vez mais cursos presenciais de formação de professores integram o uso de comunicação mediada por computador (CMC). Simultaneamente, muitos programas a distância incluem componentes face a face. Por essas razões, a separação entre as modalidades presenciais e a distância tem se tornado cada vez mais difícil de distinguir.

Hall e Knox (2009) afirmam que as tecnologias de informação e comunicação representam, para a educação de professores, que o conhecimento da comunidade discursiva (artigos de periódicos, livros e materiais de ensino) pode ser distribuído de forma mais barata e eficiente para os profissionais espalhados globalmente. Elas também fornecem novos modos de comunicação, em forma de discussões online, chats síncronos e materiais de ensino baseados na Web. Esses autores geram questionamentos a respeito dos benefícios de tais ferramentas, dos aspectos relacionados à autonomia do aprendiz e dos desafios para aprendizes e professores.

Em relação às discussões on-line, os autores coletaram as vantagens identificadas e associadas a elas em alguns estudos (como os de Hammon, 2005; Kamhi-Stein, 2000; Pachler e Daly, 2006): a possibilidade de espaço igualitário; a oportunidade para professores e aprendizes construírem uma identidade on-line, a qual eles talvez não tivessem a possibilidade de adotar em contextos face a face; a exposição de professores e alunos a mais "vozes" do que eles podem ouvir em uma interação face a face; a existência de um fórum para aprendizagem e reflexão colaborativos e feedback do colega; a possibilidade de gravar as discussões e o aprendizado; a flexibilidade 
para professores e alunos se conectarem no próprio horário, bem como lerem e escreverem no próprio ritmo; o tempo para os professores elaborarem respostas bem formuladas; a facilidade de se postar links de recursos on-line nas discussões; padrões de interação que vão além da clássica interação triádica (IRF - initiation, response, feedback/follow-up), comum em salas de aula; a oportunidade de explorar ideias novas na medida em que surgem, sem as restrições de tempo e espaço da sala de aula; o potencial para formação de uma comunidade de aprendizagem entre aprendizes, separados pela distância espacial e cultural, situados em ambientes profissionais variados.

Hall e Knox (op.cit.) afirmam que muitos profissionais e pesquisadores de educação de professores de línguas a distância acreditam que as discussões on-line têm criado um senso de colaboração e comunidade. Ao mesmo tempo, há os que duvidam que tais discussões possam resultar em uma significativa comunidade que mostre total colaboração e que as discussões on-line estimulem o aprendizado ativo e contextual, mas não o aprendizado social e reflexivo. Hall e Knox (op. cit.) afirmam ainda que há poucos estudos sobre a avaliação de discussões on-line e questionamentos não debatidos, a saber: As discussões devem ser avaliadas como parte da avaliação formal por notas de um programa? O que deve ser avaliado: domínio de tópico, qualidade de argumentação, facilidade de aprendizado entre o grupo, quantidade de leitura, cumprimento de tarefas, entusiasmo na participação, número de contribuições? Como as discussões devem ser avaliadas?

No que tange à autonomia, Hall e Knox (2009) entendem que a literatura frequentemente relaciona o aprendizado a distância com as noções de independência e autonomia. Para esses autores, tais termos adquirem uma conotação diferente daquela geralmente encontrada em contextos presenciais, de autoestudo. $\mathrm{Na}$ educação a distância, a autonomia parece ser um estado da mente e assemelha-se mais com a noção de interdependência, em que há fortes conexões com visões colaborativas e construtivistas de conhecimento e educação. Em relação aos desafios para professores e aprendizes, os autores mencionam, como problemas da educação a distância, o isolamento, a falta de ajuda imediata do colega, as altas taxas de desistência, os problemas na comunicação, as exigências de tempo oneroso para 
professores e alunos, além do fato de que o status dos programas a distância ainda é problemático e questionável em muitos países. Para os autores, em virtude da natureza globalizada da educação de professores a distância e da necessidade de muitos estudantes de que suas qualificações sejam reconhecidas globalmente, são necessárias investigações sobre a viabilidade dos mecanismos internacionais para avaliar a qualidade de tais programas.

Nesse sentido, Reinders (2009, p. 234) cita as estratégias necessárias para o sucesso de um programa de formação de professores com tecnologia, as quais são enumeradas a seguir.

1. Bom acesso a computadores com suporte tecnológico contínuo.

2. Tempo, ambos antes e após o curso, para os participantes aprenderem sobre e então implementarem o que foi desenvolvido e assim conseguirem subsequente reconhecimento de seus trabalhos.

3. Construção de tarefas autênticas relacionando teoria e prática por meio de exemplos e aplicativos para ir além do entendimento da tecnologia, chegandose à compreensão de como a tecnologia pode ser implementada na situação de aprendizagem.

4. Experiência com tecnologia sob a perspectiva do aprendiz, em outras palavras, aprender sobre tecnologia com tecnologia.

5. Disponibilidade de suporte permanente, por exemplo, por meio de um programa de mentores ou de uma comunidade de prática.

6. Oportunidades e encorajamento para refletir sobre as implicações da tecnologia em um nível mais amplo.

Segundo o autor, o formador está em uma posição delicada, uma vez que precisa explicitar os benefícios da inovação para o contexto da sala de aula. Na verdade, a situação de inovação não é nada nova para a educação: tecnologias de sucesso, como a caneta, o papel, a lousa, tornaram-se invisíveis, chegando ao ponto de não as reconhecermos mais como tecnologias. Hall e Knox (2009), entretanto, vêm como vantagem a "visibilidade" das novas tecnologias uma vez que ela encoraja o foco em pesquisas sobre a maneira como elas 
medeiam aprendizagem e o ensino (e poderíamos adicionar a formação do professor neste rol).

Na próxima seção do artigo, explicitaremos duas propostas de formação de professores em CALL no contexto brasileiro.

\section{Formação de professores línguas em CALL no contexto brasileiro}

No estado de São Paulo, algumas iniciativas para a integração da formação tecnológica na formação inicial e continuada de professores de línguas têm sido feitas por universidades públicas e particulares, como a Unesp e a PUC-SP.

O projeto Teletandem Brasil: línguas estrangeiras para todos, da Unesp, tem uma agenda educacional que abrange as áreas de ensino e aprendizagem de línguas estrangeiras mediados por computadores e de desenvolvimento de professores em contexto de aprendizagem virtual. Telles (2009) descreve a proposta do teletandem:

Adotando uma visão pioneira e ao mesmo tempo revitalizante e prática dos princípios de colaboração, reciprocidade e autonomia do tandem, uma equipe de linguistas aplicados do Programa de Pós-Graduação em Estudos Linguísticos da Universidade Estadual Paulista deu o nome de Teletandem quando ele é realizado em um contexto virtual, assistido pelo computador, à distância, via comunicação síncrona, por meio da utilização dos recursos de escrita, leitura, e videoconferência de aplicativos de mensagens instantâneas (Skype, Windows Live Messenger, OoVoo, por exemplo). No que diz respeito aos recursos humanos e técnicos, para se realizar um teletandem são necessários: (a) um par de falantes de línguas diferentes que desejem falar a língua um do outro; (b) um computador com aplicativo de mensagens instantâneas e conectado a rede por um modem ADSL e (c) uma webcam. Isso é feito de forma completamente gratuita, por meio das ferramentas de leitura, escrita (chat e quadro de comunicação), áudio e vídeo. Este acesso gratuito por meio da web proporciona aos alunos o contato com as línguas e culturas estrangeiras a um baixo 
custo, além do estabelecimento de parcerias, amizades e trocas de informações culturais entre ambas as partes. (TELLES, 2009, p.17)

Para Telles (2009, p.67), “a metamorfose exercida pelas TICs sobre as condições de promoção de contatos interlinguísticos e interculturais" faz surgir demandas como a de "pensar a educação de línguas estrangeiras dos pontos de vista que deem conta dos aspectos sociais do desenvolvimento humano (tais como o sócio-interacionismo Vygotskyano), da aprendizagem colaborativa e da autonomia".

$\mathrm{O}$ projeto Teletandem visa articular ensino, pesquisa $\mathrm{e}$ extensão. Um de seus objetivos de pesquisa é de "investigar os quesitos necessários à formação inicial e continuada do professor e seu papel de professor e mediador da aprendizagem em um novo contexto interativo de ensino/ aprendizagem de línguas estrangeiras in-tandem a distância" (VIEIRA-ABRAHÃO, 2010, p.219).

Segundo Vieira-Abrahão (2010), as investigações sobre formação de professores conduzidas no projeto, até agora, foram todas de natureza etnográfica e tiveram por participantes pares formados por alunos de Letras e alunos universitários estrangeiros da área de formação de professores ou não, envolvidos no teletandem, denominados interagentes. Os pares de interagentes dentro do projeto foram supervisionados por alunos de pós-graduação - doutorandos e mestrandos - da Unesp (denominados no projeto como mediadores), papel que também foi enfocado em algumas das pesquisas. Segundo a autora, a fundamentação teórica comum às investigações baseou-se em estudos sobre a cognição de professores, a formação de professores e a tecnologia no ensino de línguas.

Em uma análise das conclusões de pesquisas de mestrado e de doutorado orientadas por ela no projeto Teletandem voltadas à formação de professores (SALOMÃO, 2008; BEDRAN, 2008; MESQUITA, 2008; KANEOYA, 2008; MENDES, 2009), a autora conclui:

Tecendo uma conclusão da análise realizada até o momento, posso afirmar ser o Teletandem um espaço promissor para a formação de professores em pré-serviço, uma vez que proporciona o envolvimento do futuro professor em uma 
prática real de ensinar e aprender, promove o acompanhamento próximo de um formador, proporciona discussões de objetivos, procedimentos e técnicas e os resultados de suas implementações à luz de teorias contemporâneas, trazidas ao processo de formação de acordo com as necessidades geradas pelo processo de ensino e aprendizagem, e promove condições para o desenvolvimento do processo reflexivo e da autonomia docente. Além disso, parece ser um espaço para o ensino e aprendizagem em contextos reais, com foco na negociação e construção de significados, que possibilita o desenvolvimento das competências pedagógica, linguísticocomunicativa e intercultural (VIEIRA-ABRAHÃO, 2010, p.242).

Outro projeto que também busca a integração entre extensão, pesquisa e docência é o curso "Teachers' Links: reflexão e desenvolvimento para professores de inglês", promovido pelo programa de Pós-Graduação em Linguística Aplicada e Estudos da Linguagem - LAEL, da Pontifícia Universidade Católica de São Paulo - PUC-SP e implementado pela coordenadoria de Extensão, Aperfeiçoamento e Especialização - COGEAE (COLLINS, 2009). Segundo Collins (2009, p.16), o curso representa uma experiência integrada uma vez que é "planejado, implementado e observado crítica e reflexivamente, gerando então problemas e questões de pesquisa cujas soluções e respostas alimentam novas ações de planejamento e ensino".

Segundo a autora, os objetivos centrais do curso são oferecer aos professores "oportunidade para o aperfeiçoamento de seu desempenho em língua inglesa, de sua capacidade de reflexão crítica sobre o seu papel no ensino, de sua capacidade de planejar e organizar sua ação docente e de sua habilidade para usar as tecnologias de informação e comunicação" (COLLINS, 2009, p. 16).

A autora explicita ainda os pilares do curso: a teoria sóciointeracionista, que dá suporte às noções de mediação e interação, e a reflexão por meio de Comunidade de Investigação (Community of Inquiry). Para ela, alguns dos resultados mais significativos obtidos até o momento, ao longo dos dez anos de existência do projeto, relacionam-se à mediação semiótica, especialmente aquela 
desenvolvida em fóruns de discussão assíncrona. Nas palavras da autora:

\begin{abstract}
Para fazer uma mediação bem sucedida, o professor necessita ter clareza da sua intencionalidade e focalizar os aspectos cognitivos, mas ir além, considerando os aspectos afetivos, sociais e culturais no processo de aprendizagem. A mediação pedagógica exige do professor abertura para aprender, flexibilidade, postura reflexiva para rever constantemente a sua prática, criticidade e autonomia para acompanhar o aluno-aprendiz. (COLLINS, 2009, p.26)
\end{abstract}

Outras áreas cujos progressos têm sidos significativos, segundo a autora, são a "do exercício discursivo cada vez mais claro das presenças social, cognitiva e de ensino", por meio da análise da comunicação síncrona e assíncrona no âmbito do curso; os "estudos sobre a complexidade do design e da construção do hipertexto e hipermídia", os estudos sobre a desistência e sobre a reflexão (p.2627).

Ambas as propostas, da Unesp e da PUC, trazem em seu bojo a colaboração e a interação como bases para a aprendizagem do professor em contextos de CALL, uma tendência interacional dos cursos a distância na atualidade, advinda de pressupostos da teoria sociocultural. O letramento digital, em ambos os casos, parece fazer parte da formação, está integrado aos aspectos pedagógicos, o que a nosso ver constitui um dos pontos cruciais para vencermos a separação entre teoria e prática na introdução das tecnologias no ensino e aprendizagem de línguas e na formação de professores em CALL.

\title{
5. Considerações finais
}

Neste artigo, buscamos trazer à tona uma discussão sobre questões relacionadas à integração das novas tecnologias à formação do professor de línguas estrangeiras na atualidade. Os dois exemplos de propostas de formação de professores com o uso de tecnologias no Brasil explicitados neste artigo, o Projeto Teletandem Brasil, da Unesp, e o Teachers' Links, da PUC-SP, conjugam alguns dos 
elementos essenciais para o desenvolvimento de professores em CALL: a perspectiva sociocultural, a colaboração e a interdependência. Desse modo, tais projetos nos mostram alguns caminhos para conjugar a prática e a teoria na formação do professor para e com uso das novas tecnologias na contemporaneidade.

Acreditamos ser necessário que os cursos de formação inicial e continuada introduzam as novas tecnologias na formação do professor utilizando-se de infraestrutura institucional, apoio técnico e pedagógico com objetivos bem definidos que levem os professores a compreenderem a relação entre o conhecimento sobre o uso das novas ferramentas tecnológicas em diferentes contextos de ensino e aprendizagem. Entendemos que, além de promoverem a aprendizagem sobre a ferramenta, as propostas devem conjugar tal aprendizagem ao uso dessas ferramentas em situações de ensino que possam levar o professor a empregá-las na prática e refletir sobre seu uso, colaborativamente com seus pares. A ideia da conjugação de ensino, aprendizagem e pesquisa, que contextualiza e retroalimenta os projetos de formação nesses casos, auxiliará a construção do aparato teórico sobre a formação de professores em CALL.

\section{Referências}

BEDRAN, Patrícia. F. A (re) construção de crenças sobre língua, ensino e aprendizagem na interação dos professores mediadores e dos pares interagentes no Teletandem. (424f.) Dissertação (Mestrado em Estudos Linguísticos) - Instituto de Biociências, Letras e Ciências Exatas, Universidade Estadual Paulista, São José do Rio Preto, 2008.

COLLINS, Heloísa. Formação continuada para professores de inglês: uma experiência de integração entre docência, pesquisa e extensão. In: TELLES, J.A. (Org.). Formação inicial e continuada de professores de línguas: dimensões e ações na pesquisa e na prática. Campinas: Pontes, 2009. p. 15-28.

CHAPELLE, Carol A. Foreword. In: HUBBARD, Philip; LEVY, Mike. Teacher education in CALL. Amsterdam/Philadelphia: Benjamin Publishing Company, 2006. p. VII-VIII. 
HALL, David R.; KNOX, John S. Language teacher education by distance. In: BURNS, Anne; RICHARDS, Jack C. (Eds.). Second language teacher education. Cambridge: Cambridge University Press, 2009. p. 218-229.

HUBBARD, Philip; LEVY, Mike. The scope of CALL education. In: HUBBARD, Philip; LEVY, Mike. Teacher education in CALL. Amsterdam/Philadelphia: Benjamin Publishing Company, 2006. p. 322.

HUBBARD, Philip. CALL and the future of language teacher education. CALICO Journal, v. 25, n. 2, p. 175-188, 2008.

JOHNSON, Karen E. Second language teacher education: a sociocultural perspective. 1. ed. New York: Routledge, 2009.

KANEOYA, Marta L. C. F. A formação inicial de professoras de línguas paralem contexto mediado pelo computador (teletandem): um diálogo entre crenças, discurso e reflexão profissional. (263f.) Tese (Doutorado em Estudos Linguísticos) - Instituto de Biociências, Letras e Ciências Exatas, Universidade Estadual Paulista, São José do Rio Preto, 2008.

MENDES, Ciro M. Crenças sobre a língua inglesa: antiamericanismo e suas influências no processo de ensino-aprendizagem de professores em formação. (203 p.). Dissertação (Mestrado em Estudos Lingüísticos) - Instituto de Biociências, Letras e Ciências Exatas, Universidade Estadual Paulista, São José do Rio Preto, 2009.

MESQUITA, Alexandre A. F. Crenças e práticas de avaliação no processo interativo e na mediação de um par no tandem à distância: um estudo de caso. (251 p.) Dissertação (Mestrado em Estudos Lingüísticos) - Instituto de Biociências, Letras e Ciências Exatas, Universidade Estadual Paulista, São José do Rio Preto, 2008.

REINDERS, Hayo. Technology and second language teacher education. In: BURNS, Anne; RICHARDS, Jack C. (Eds.). Second 
language teacher education. Cambridge: Cambridge University Press, 2009. p. 230-237.

RICHARDS, Jack C. Technologies in the classroom. In __; RENANDYA, Willy A. (Eds.). Methodology in language teaching: an anthology of current practice. Cambridge, Cambridge University Press, 2002. p. 361-363.

SALOMÃO, Ana Cristina B. Gerenciamento e estratégias pedagógicas na mediação dos pares no Teletandem e seus reflexos para as práticas pedagógicas dos interagentes. Dissertação de Mestrado. 316 f. São José do Rio Preto, UNESP, Instituto de Biociências, Letras e Ciências Exatas, 2008.

TELLES, João A. Teletandem: um contexto virtual, autônomo $e$ colaborativo para aprendizagem de línguas estrangeiras no século XXI. Campinas: Pontes, 2009.

VIEIRA-ABRAHÃO, Maria Helena. Teletandem Brasil - línguas estrangeiras para todos: um espaço para a formação de professores de línguas. In: BENEDETTI, Ana Mariza; CONSOLO, Douglas A.; VIEIRA-ABRAHÃO, Maria Helena. (Orgs.). Pesquisas em ensino e aprendizagem no Teletandem Brasil: línguas estrangeiras para todos. Campinas: Pontes, 2010. p. 219-242.

Recebido em: 06/01/2012

Aceito em:

$04 / 12 / 2012$

Title: Language teacher education in CALL: history and perspectives 
A educação de professores de línguas em CALL 